Sensory neuronopathy is a well-recognized remote effect of carcinoma. We report the clinical and electrodiagnostic evolution of a sensory neuronopathy in a patient with carcinoma of the lung. Serial electrophysiologic studies suggest transformation from normal peripheral nerve function through early posterior root involvement to absent sensory nerve function. Diffuse motor conduction abnormalities occurred late in the disease, perhaps reflecting motor axon changes associated with disuse.

Key words: neuropathy $\bullet$ sensory neuronopathy $\bullet$ carcinomatous neuropathy $\bullet$ remote effect neuropathy

MUSCLE \& NERVE 12:508-513

1989

\title{
ELECTRODIAGNOSTIC EVOLUTION OF CARCINOMATOUS SENSORY NEURONOPATHY
}

PETER D. DONOFRIO, MD, ANTHONY G. ALESSI, MD,

JAMES W. ALBERS, MD, PhD, ROBERT H. KNAPP, MD,

and MILA BLAIVAS, MD, PhD

Although the neuropathies associated with carcinoma are heterogenous, the most distinctive is the sensory neuronopathy first described clinically and pathologically by Denny-Brown. ${ }^{9}$ We report the electrophysiologic evolution of a remote-effect sensory neuronopathy in a patient with autopsyproven small cell carcinoma.

\section{CASE PREsentation}

A 45-year-old woman was referred with a 4-week history of muscle and joint stiffness, fatigue, fever, weight loss, and right facial numbness. Initial examination identified nystagmus on right voluntary gaze, diminished right facial sensation, mild upper extremity dystaxia, axial titubation, and unsteady tandem gait. Muscle stretch reflexes were brisk,

From the Departments of Neurology (Drs. Donofrio, Alessi, and Albers) and Pathology (Dr. Blaivas), University of Michigan Medical Center, Ann Arbor, Michigan, and the Department of Pathology, Michigan State University School of Medicine, Lansing, Michigan (Dr. Knapp)

Presented in part at the thirty-third annual meeting of the American Association of Electromyography and Electrodiagnosis, Boston, Massachusetts, September 1986

Dr. Donofrio's current address is Department of Neurology, Bowman Gray School of Medicine, Winston-Salem, North Carolina 27103

Address reprint requests to Dr. Donofrio at the Department of Neurology, Bowman Gray School of Medicine, 300 South Hawthorne Road, WinstonSalem, North Carolina 27103.

Accepted for publication June 6, 1988.

$0148-639 \times / 1206 / 0508 \$ 04.00 / 6$

C 1989 John Wiley \& Sons, Inc. and a mild reduction in vibratory perception was recorded at her toes. During her initial hospitalization, she developed a left tonic pupil and central facial weakness, sensorineural hearing loss, constipation, and orthostatic hypotension. Axial titubation and gait worsened, muscle stretch reflexes disappeared, and sensory loss progressed. She began to complain of severe extremity dysesthesias. Despite extensive laboratory and radiologic testing, she was discharged without a diagnosis.

She was subsequently readmitted for cachexia, dysphagia, worsening dysesthesias, and weakness. Physical examination demonstrated bilateral tonic pupils, course nystagmus in all directions of gaze, choreoathetoid movements, and pronounced sensory loss to all modalities. Her condition deteriorated, and she eventually required nasogastric tube feeding and intubation because of respiratory failure.

Laboratory studies of blood and urine continued to be normal. Cerebrospinal fluid (CSF) analysis revealed 3-7 WBCs (lymphocytes), a protein of $0.22 \mathrm{~g} / \mathrm{L}$ (normal $\leq 0.045$ ), and $3-4$ oligoclonal bands (no corresponding bands detected in the serum). Brain CT scan and MRI were normal as were visual, brainstem, and somatosensory evoked studies. Chest CT scan identified a $11 / 2 \mathrm{~cm}$ left hilar mass. Sural nerve biopsy showed marked loss of large and small myelinated fibers but no amyloid deposition (Fig. 1). Teased fiber preparations 


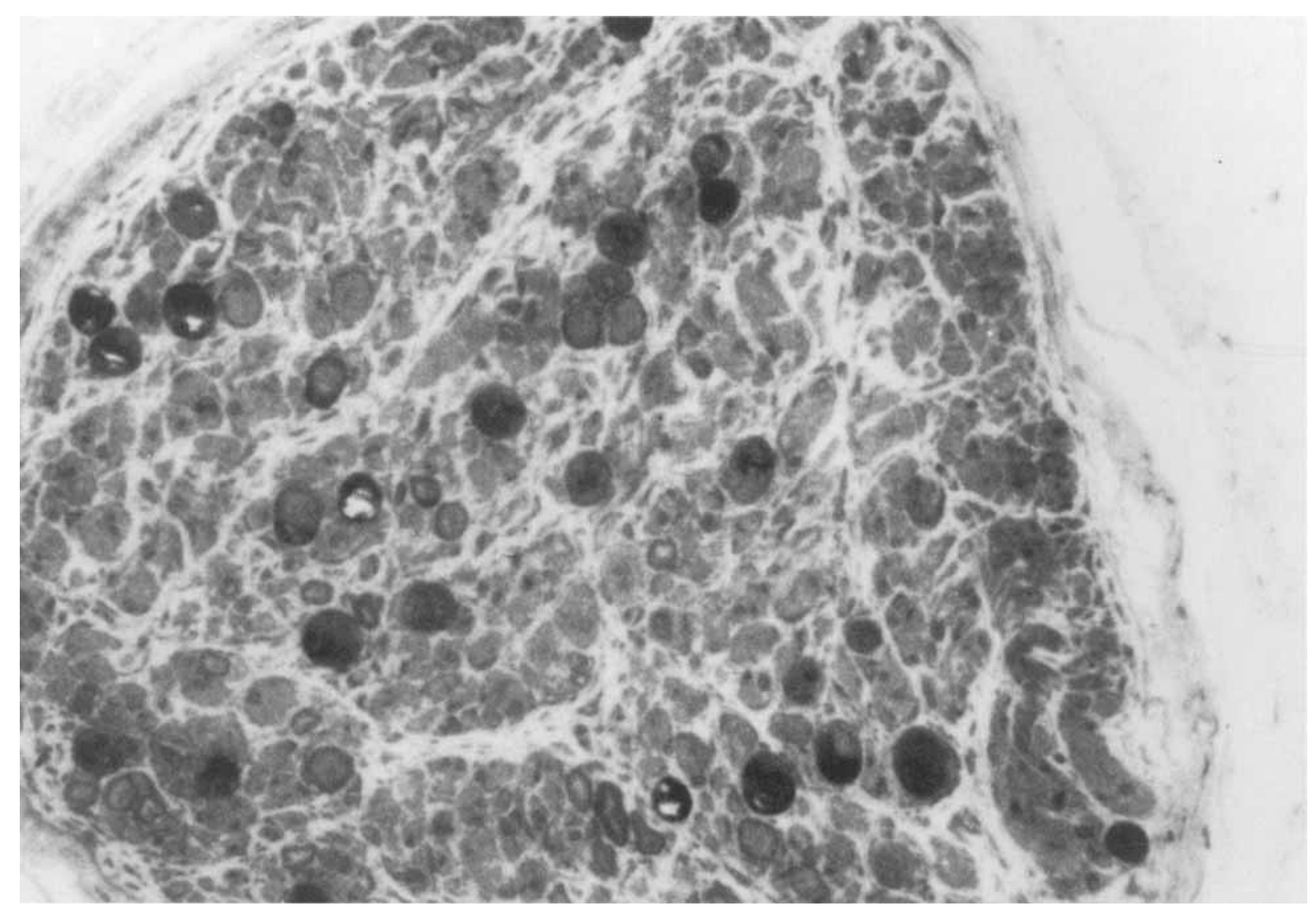

FIGURE 1. Epon-embedded, $1 \mu \mathrm{m}$-thick section of sural nerve stained with toluidine blue. Magnification $75 \times$. A fascicle shows marked loss of both large and small myelinated fibers as well as disintegration of the present fibers.

revealed changes characteristic of ongoing axonal degeneration and minimal segmental myelin degeneration.

The patient expired from pulmonary congestion 8 months after disease onset. Necropsy demonstrated a left hilar undifferentiated small cell carcinoma, severe pulmonary congestion, and cardiomegaly. Neuropathologic findings revealed severe dorsal column degeneration (Fig. 2) and prominent neuronal loss in the dorsal root ganglia (Fig. 3), changes previously reported in carcinomatous sensory neuronopathy. No ventral horn abnormalities were observed; no malignant cells were recovered from the spinal cord or CSF.

\section{MATERIALS AND METHODS}

Motor and sensory conduction studies were performed using standard techniques of supramaximal percutaneous stimulation and surface electrode recording. Compound muscle action potential (CMAP) and sensory nerve action potential (SNAP) amplitudes were measured from baseline to negative peak. Conduction velocity (CV) was measured in the forearm and leg segment. Fresponse latencies were recorded as the minimal latency in a series of $10 \mathrm{~F}$ responses using distal (wrist or ankle) antidromic motor nerve stimulation. Posterior tibial $\mathrm{H}$-reflex latencies were determined as the shortest latency of the largest H-reflex amplitude recorded on successive stimulations. Skin temperatures were measured and maintained above $32^{\circ} \mathrm{C}$ using warm compresses.

Electromyography was performed using standard concentric needle electrodes. Insertional activity, spontaneous activity at rest, and motor unit recruitment and morphology were analyzed and scored subjectively.

\section{ELECTRODIAGNOSTIC RESULTS}

Table 1 displays serial nerve conduction results at various intervals after disease onset. These results can be summarized as follows: day 29, normal nerve conduction studies; day 39 , normal sensory 


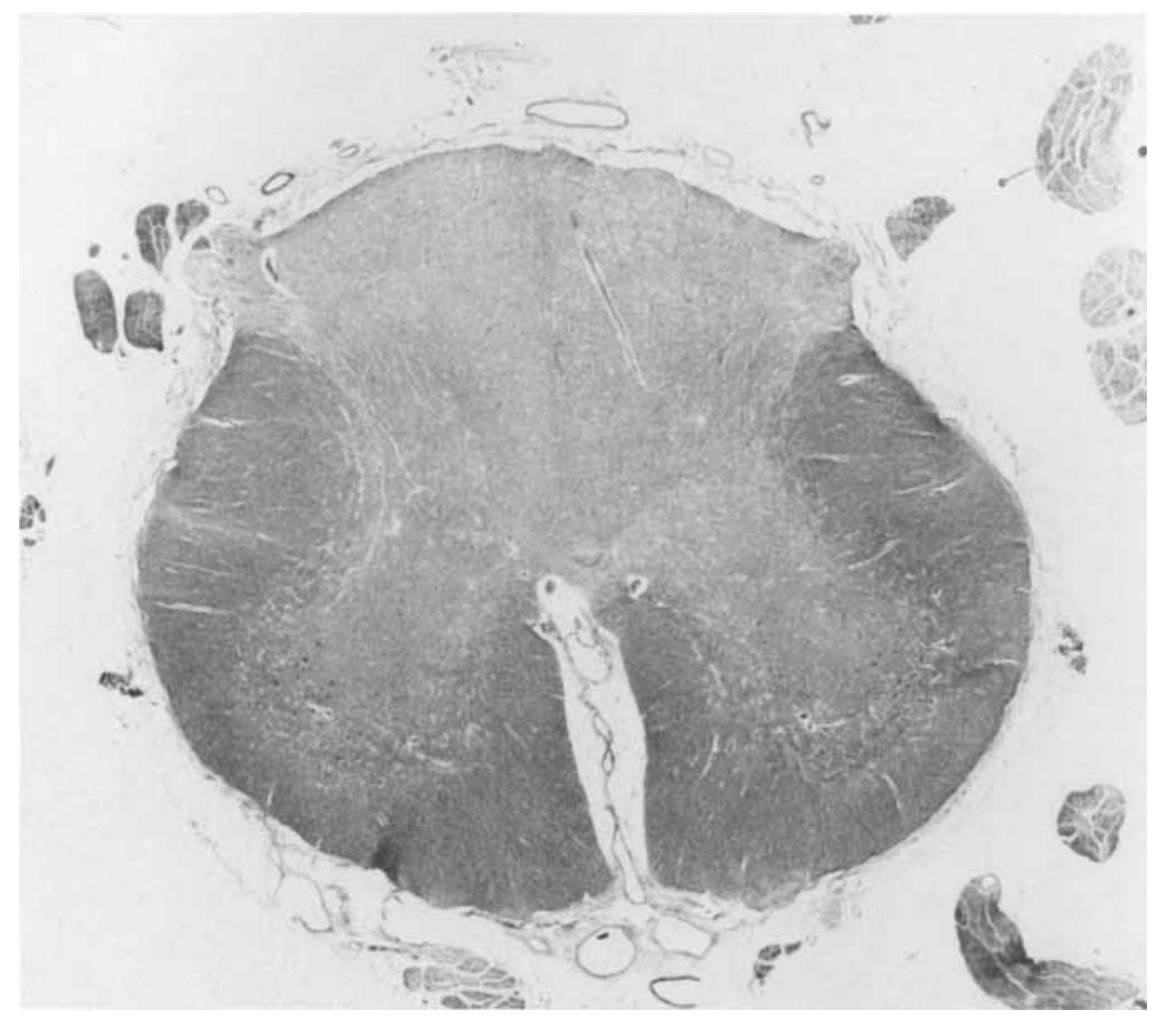

FIGURE 2. LFB-PAS stain of cross section of lumbar spinal cord. Magnification $8 \times$. Degeneration of the dorsal columns. Note loss of myelin secondary of degeneration of dorsal root ganglion. This was a prominent finding throughout the entire length of the spinal cord.

conduction studies, absent $\mathrm{H}$ reflexes, and slowing in 1 motor GV; day 68, absent or reduced SNAP amplitudes, prolonged ulnar sensory distal latency, absent $\mathrm{H}$ reflexes, and slowing in 1 motor CV; days 104-110, absent sensory responses, reduced CMAPs, slowing in motor CVs, and a prolonged F-response latency. The needle cxamination was normal at all evaluations, except for unsustained positive waves and fibrillation potentials in distal lower extremity muscles recorded during the fifth study. Figure 4 represents graphically the sequential conduction study results of one sensory and one motor nerve in the evolution of the remote-effect neuronopathy.

\section{DISCUSSION}

In most retrospective studies, neuropathy as a remote-effect of carcinoma has been detected clinically in $1.7-5.5 \%$ of patients. ${ }^{5,8,18}$ These percentages increase to $17-80 \%$ in prospective studies when electrodiagnostic and morphometric criteria are utilized. ${ }^{13,14,22,31}$ The carcinomatous neuropathies are heterogenous in clinical presentation and morphology, consisting of a distal sensorimotor axonopathy, ${ }^{5,6,8,23}$ a sensory neurono- pathy, ${ }^{4-6,8,9,15}$ and rare occurrences of chronic inflammatory demyelinating polyneuropathy $y^{5,26}$ and paraneoplastic vasculitic neuropathy. ${ }^{16}$ Although less frequent than the distal sensorimotor axonopathy, the most commonly identified neuropathy with carcinoma is the sensory neuronopathy first described in detail by Denny-Brown. ${ }^{9}$ This neuropathy is subacute in onset and may precede identification of the neoplasm by several months. It is strongly associated with oat cell carcinoma of the lung. Symptoms and signs include pain, paresthesias, dysesthesias, and prominent large more than small fiber sensory loss. Areflexia, gait ataxia, and choreoathetoid movements are common, whereas strength is usually preserved. Less common manifestations are facial hypesthesias, nystagmus, depressed or unreactive pupils, and hearing loss. ${ }^{15}$ The protein concentration of the CSF is frequently elevated, ${ }^{5,15}$ and oligoclonal bands may be detected. ${ }^{21}$ Neuropathology reveals inflammation, cell loss, and degeneration of dorsal root ganglia and posterior roots and gliosis of the posterior columns of the spinal cord. ${ }^{5,9.15}$ Similar findings occur in peripheral sensory nerves. ${ }^{15}$ Skeletal muscle may show grouped atrophy. ${ }^{15}$ 


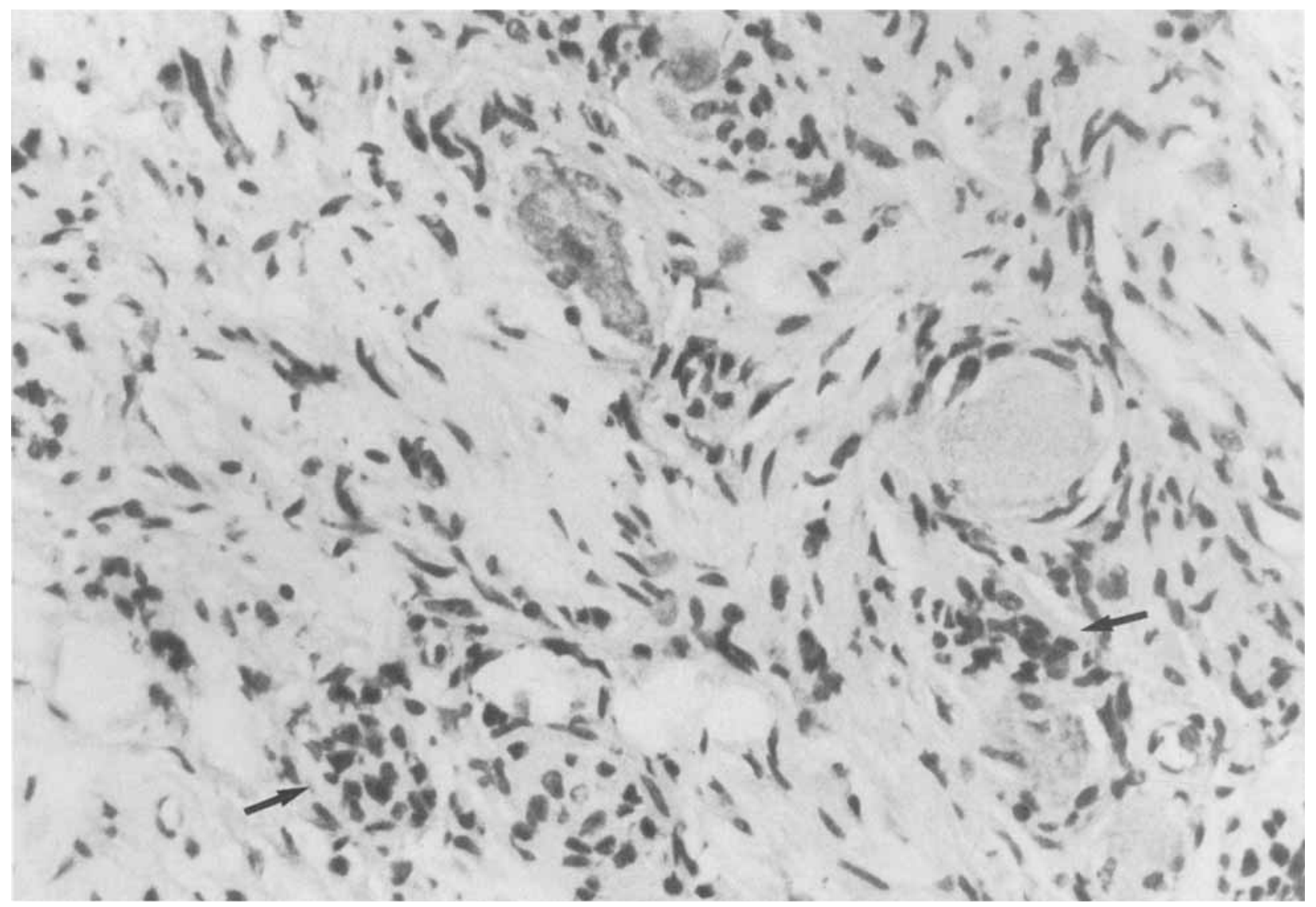

FIGURE 3. Hematoxylin \& eosin stain of dorsal root ganglion. Magnification $250 \times$. There is a prominent loss of axons. There are tight clusters of dark staining capsule cells which proliferate in place of the degenerated neurons; i.e., nodules of Nageotte (arrows).

Reports of nerve conduction studies in fully developed carcinomatous sensory neuronopathy have demonstrated uniform results. ${ }^{15}$ SNAP amplitudes are diminished or absent in the setting of normal motor nerve conduction. Motor amplitudes and conduction may be slightly reduced in severe cases, perhaps representing disuse atrophy, axonal stenosis, or a combination of both. ${ }^{10,13,28}$ Also normal is the needle examination except in late, severe disease when spontaneous activity at rest and irregular recruitment of voluntary motor units may be recorded. ${ }^{13}$ This pattern of electrodiagnostic findings, although suggestive of carcinomatous neuronopathy, is not pathognomonic. Similar abnormalities have been reported in chronic idiopathic ataxic neuropathy, ${ }^{7}$ chronic biliary cirrhosis, ${ }^{3}$ paraproteinemia, ${ }^{29}$ hereditary sensory neuropathy, ${ }^{24}$ Sjogren's syndrome, ${ }^{19}$ Fishervariant Guillain-Barré syndrome, ${ }^{1 "}$ Freidreich's ataxia, ${ }^{20,25}$ dysautonomia, ${ }^{2}$ association with penicillin administration, ${ }^{30}$ pyridoxine,${ }^{27}$ and cisplatinum toxicity, ${ }^{12}$ and in idiopathic sensory neuronopathy. ${ }^{17}$
Analysis of the serial electrodiagnostic results and the neuropathology in this case suggests that carcinomatous sensory neuronopathy may evolve in stages. Normal nerve conduction results on initial testing confirm integrity of the motor and sensory peripheral nervous system, the latter from the dorsal root ganglion distally. On subsequent testing, motor and sensory nerve conduction studies remain normal in the setting of absent $\mathrm{H}$ reflexes. This unique combination of nerve conduction abnormality suggests dysfunction of the $\mathrm{H}$ reflex arc proximal to the dorsal root ganglia and ventral horn. Thereafter, diminution and disappearance of sensory responses, in the setting of relatively normal motor conduction, implies progression of the disease to the dorsal root ganglia and/or sensory nerve. The generalized motor nerve conduction abnormalities, which evolved later in the illness, could be attributed to a subclinical motor component of a sensorimotor polyneuropathy, another form of paraneoplastic neuropathy. A more likely explanation would be the recently described effect of disuse on motor 


\begin{tabular}{|c|c|c|c|c|c|}
\hline & \multicolumn{5}{|c|}{ Days following onset of initial symptoms } \\
\hline & 29 & 39 & 68 & 104 & $\uparrow 10$ \\
\hline \multicolumn{6}{|l|}{ Sensory nerves } \\
\hline \multicolumn{6}{|l|}{ Sural } \\
\hline Amp. $(\geq 6 \mu V)$ & 12 & 12 & NR & NR & - \\
\hline $\mathrm{DL}(\leq 4.2 \mathrm{msec})$ & 3.9 & 3.9 & & & \\
\hline \multicolumn{6}{|l|}{ Median } \\
\hline Amp. $(\geq 20 \mu \mathrm{V})$ & 30 & - & NR & NR & - \\
\hline $\mathrm{CV}(\geq 53 \mathrm{~m} / \mathrm{sec})$ & 63 & - & & & \\
\hline $\mathrm{DL}(\leq 3.7 \mathrm{msec})$ & 3.4 & - & & & \\
\hline \multicolumn{6}{|l|}{ Uinar } \\
\hline Amp. $(\geq 10 \mu \mathrm{V})$ & - & - & 5 & NR & - \\
\hline $\mathrm{CV}(\geq 53 \mathrm{~m} / \mathrm{sec})$ & - & - & & & \\
\hline $\mathrm{DL}(\leq 3.5 \mathrm{msec})$ & - & - & 4.8 & & \\
\hline \multicolumn{6}{|l|}{ Motor nerves } \\
\hline \multicolumn{6}{|l|}{ Posterior tibial } \\
\hline Amp. $(\geq 3 \mathrm{mV})$ & $12 / 11$ & 13 & $16 / 10$ & $9 / 7$ & 7 \\
\hline $\mathrm{CV}(\geq 41 \mathrm{~m} / \mathrm{sec})$ & 48 & 41 & 41 & 36 & 35 \\
\hline $\mathrm{DL}(\leq 6.1 \mathrm{msec})$ & 4.0 & 4.5 & 4.1 & 5.1 & 7.0 \\
\hline F response ( $\leq 55 \mathrm{msec})$ & - & 51.2 & 49 & 57.6 & 60.4 \\
\hline \multicolumn{6}{|l|}{ Ulnar } \\
\hline Amp. $(\geq 6 \mathrm{mV})$ & $8 / 8$ & - & $13 / 11$ & $7 / 6$ & 10 \\
\hline$C V(\geq 49 \mathrm{~m} / \mathrm{sec})$ & 61 & - & 55 & 47 & 47 \\
\hline $\mathrm{DL}(\leq 3.5 \mathrm{msec})$ & 2.5 & - & 2.6 & 2.5 & 3.1 \\
\hline$F$ response $(\leq 31 \mathrm{msec})$ & & & 29.5 & - & 30.6 \\
\hline \multicolumn{6}{|l|}{ Posterior tibial $\mathrm{H}$ reflex } \\
\hline Right/left & - & NR/NR & - NR & - & - \\
\hline
\end{tabular}

Key: $A m p-$ amplitude, $D L=$ distal latency, $C V=$ conduction velocily, dash indicates not done.

conduction. ${ }^{10}$ This effect has been demonstrated in an animal model ${ }^{10,28}$ and used to explain similar motor nerve conduction results in pyridoxine intoxication, another illness resulting in a sensory neuronopathy. ${ }^{1}$ Disuse effect on motor conduction would also correlate closely with the autopsy findings of normal ventral horns and motor roots.

The electrodiagnostic findings in sensory neuronopathy are characteristic and, although they may resemble those recorded in a distal sensorimotor polyneuropathy early in the course of evolution, the complete loss of sensory potentials in the abscnce of severe motor conduction or needle electromyographic abnormalities would be unusual in the latter condition. This pattern of abnormality should raise the question of neuronopathy, greatly limiting the differential diagnosis. The clinical features of superimposed cranial nerve and central nervous system dysfunction in this patient further raise suspicion for a paraneoplastic syndrome.

The initial conduction studies were performed at a time when the patient was symptomatic. This dichotomy between clinical and electrodiagnostic findings suggests that normal studies early in dis- ease presentation do not exclude the possibility of a peripheral process and emphasize the need for repeat electrodiagnostic evaluation when the diagnosis is unclear.

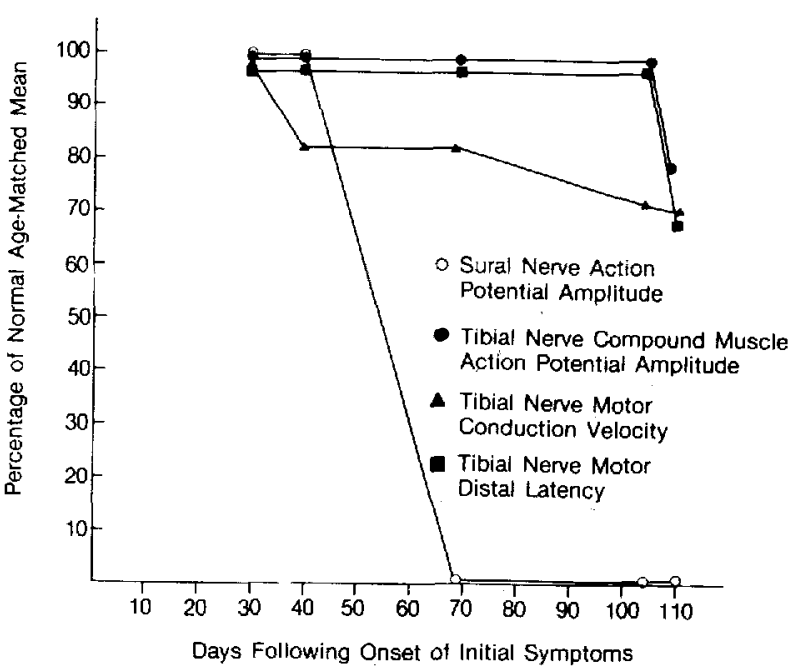

FIGURE 4. Nerve conduction results of the sural and tibial motor nerves are represented graphically relating the response expressed as a percentage of the normal age-matched mean to the course of the disease. 


\section{REFERENCES}

1. Albin RL, Albers JW, Greenberg HS, Townsend JB, Lynn RB, Burke JM, Alessi AS: Acute sensory neuropathy-neuronopathy from pyridoxine overdose. Neurology (NY) 37:1729-1732, 1987.

2. Brown JC, Johns RJ: Nerve conduction in familial dysautonomia (Riley-Day syndrome). J Am Med Assoc 201:200203, 1967

3. Charron I, Peyronnard J-M, Marchand L: Chronic Biliary Cirrhosis. Arch Neurol 37:84-87, 1980.

4. Croft PB, Henson RA, Urich II, Wilkinson PC: Sensory ncuropathy with bronchial carcinoma: a study of four cases showing serological abnormalities. Brain 88:501-514, 1965.

5. Croft $\mathrm{PB}$, Urich $\mathrm{H}$, Wilkinson $\mathrm{M}$ : Peripheral neuropathy of sensorimotor type associated with malignant disease. Brain 90:31-66, 1967.

6. Croft $\mathrm{PB}$, Wilkinson $\mathrm{M}$ : The incidence of carcinomatous neuromyopathy in patients with various types of carcinoma. Brain 88:427-34, 1965.

7. Dalakas MC: Chronic idiopathic ataxic neuropathy. Ann Neurol 19:545-554, 1986.

8. Dayan AD, Croft PB, Wilkinson M: Association of carcinomatous neuromyopathy with different histological types of carcinoma of the lung. Brain 88:435-88, 1965 .

9. Denny-Brown D: Primary sensory neuropathy with muscular changes associated with carcinoma. I Neurol Neurosurg Psychiatry 11:73-87, 1948 .

10. Grifin JW, Gold BG, Pestronk A, Stanley EF, Price DL, Fahnestock K: Experimental axonal atrophy produced by botulinum toxin. Neurology (NY) 36(suppl 1):80A, 1986.

11. Guiloff RJ: Peripheral nerve conduction in Millcr Fisher syndrome. J Neurol Neurosurg Psychiatry 40:80 -807, 1977.

12. Hcmphill M, Pestronk A, Walsh T, Parhad I, Clark A, Rosenshein N: Sensory neuropathy in cis-platinum chemotherapy. Neurology (NY) 30:429, 1980.

13. Herishanu Y, Wolf E, Taustein I, Brian S: The carcinomatous neuropathy. Europ Neurol 1:370-374, 1970.

14. Hildebrand J, Coers C: The neuromuscular function in patients with malignant tumors. Flectromyographic and histological study. Brain 90:67-82, 1967.

15. Horwich MS, Cho L, Porro RS, Posner JB: Subacute sensory neuropathy: a remote effect of carcinoma. Ann Neurol $2: 7-19,1977$.

16. Johnson PC, Rolak LA, Hamilton RH, Laguna JF: Paraneoplastic vasculitis of nerve: a remote effect of cancer. Ann Neurol 5:437-444, 1979.

17. Kaufman MD, Iopkins LC, Hurwitz BJ: Progressive sensory neuropathy in paricnts without carcinoma: a disorder with distinctive clinical and electrophysiological findings. Ann Neurol 9:237-242, 1981 .

18. Kelly Jr JJ, Kylc RA, O'Brien PC, Dyck PJ: Prevalence of monoclonal protein in peripheral neuropathy. Neurology (NY) $31: 1480-1483,1981$.

19. Malinow K, Yannakakis GD, Glusman SM, Edlow DW, Griffin J, Pestronk A, Powcll DL, Ramsey-Goldman R, Eidelmanı BH, Medsger TA, Alexander EL: Subacute scnsory neuronopathy secondary to dorsal root ganglionitis in primary Sjogren's syndrome. Ann Neurol 20:535-537, 1986.

20. McLeod JG: An electrophysiological and pathological study of peripheral nerve in Freidreich's ataxia. $J$ Neurol Sri 12:333-349, 1971.

21. Miller JR, Burke AM, Bever CT: Occurrence of oligoclonal bands in multiple sclcrosis and other CNS diseases. Ann Neurol 13:53-58, 1983.

22. Moody JF: Electrophysiological investigations into the neurological complications of carcinoma. Brain 88: I023-1036, 1965.

23. Morton DL, Itabashi HH, Grimes OF: Nonmetastatic neurological complications of bronchogenic carcinoma: The carcinomatous neuromyopathies. I Thoracic Cardiovasc Surg $51: 14-29,1966$

24. Ohta M, Ellefson RD, Lambert EH, Dyck PJ: Hereditary sensory neuropathy, type II. Arch Neurol 29:23-27, 1973.

25. Peyronnard JM, Lapointe L, Bouchard JP, Lamontague A, Lemieux B, Barbeau A: Nerve conduction studies and electromyography in Freidreich's ataxia. Can J Neurol Sci $3: 313-317,1976$.

26. Rae-Grant AD, Feasby TE, Brown WF, Gilbert JJ, Iahn $\mathrm{AH}$ : A reversible demyelinating polyneuropathy associated with cancer. Neurology (NY) 36(suppl 1):81, 1986.

27. Schaumberg II, Kaplan J, Windebank A, Vick N, Rasmus S, Pleasure D, Brown MJ: Sensory neuropathy from pyridoxine abuse. New Engl J Med 309:445-448, 1983.

28. Sladky JT, Yue Xu, Brown MJ: Transient ataxia after acute pyridoxine intoxication: electrophysiologic and neuropathologic correlations. Neurology (NY) 37(suppl 1):376A, 1987 .

29. Smith T, Sherman W, Olarte MR, Lovelace RE: Peripheral neuropathy associated with plasma cell dyscrasia: a clinical and electrophysiological follow-up study. Acta Neurol Scand $75: 244-248,1987$

30. Sterman AB, Schaumburg IIHI, Asbury AK: The acute sensory neuronopathy syndrome: a distinct clinical entity. Ann Neurol 7:354-358, 1980.

31. Trojaborg W, Frantzen E, Andersen I: Peripheral neuropathy and myopathy associated with carcinoma of the lung. Brain 92:71-82, 1969. 